\title{
Pharmaceutical Quality/CMC Quality Benchmark Terminology
}

National Cancer Institute

\section{Source}

National Cancer Institute. Pharmaceutical Quality/CMC Quality Benchmark Terminology. NCl Thesaurus. Code C133860.

A category of terminology used to qualify the information pertaining to quality benchmarks in the framework of the Pharmaceutical Quality/Chemistry, Manufacturing and Controls documents. 